\title{
Use of blood-sparing surgical techniques and transfusion algorithms: association with decreased blood administration in children undergoing primary open craniosynostosis repair
}

\author{
Thanh T. Nguyen, MD, ${ }^{1}$ Sarah Hill, DNP, APRN, ${ }^{2}$ Thomas M. Austin, MD,, 1 Gina M. Whitney, MD, ${ }^{3}$ \\ John C. Wellons III, MD, MSPH, ${ }^{4}$ and Humphrey V. Lam, MD ${ }^{1}$
} Departments of ${ }^{1}$ Anesthesiology, ${ }^{2}$ Nursing, and ${ }^{4}$ Neurosurgery and Pediatrics, Vanderbilt University, Nashville, Tennessee; and
${ }^{3}$ Department of Anesthesiology, University of Colorado, Aurora, Colorado

\begin{abstract}
OBJECT Craniofacial reconstruction surgery (CFR) is often associated with significant blood loss, coagulopathy, and perioperative blood transfusion. Due to transfusion risks, many different approaches have been used to decrease allogeneic blood transfusion for these patients during the perioperative period. Protocols have decreased blood administration during the perioperative period for many types of surgeries. The object of this study was to determine if a protocol involving blood-sparing surgical techniques and a transfusion algorithm decreased intraoperative blood transfusion and blood loss.

METHODS A protocol using transfusion algorithms and implementation of blood-sparing surgical techniques for CFR was implemented at Vanderbilt University on January 1, 2013. Following Institutional Review Board approval, blood loss and transfusion data were gathered retrospectively on all children undergoing primary open CFR, using the protocol, for the calendar year 2013. This postprotocol cohort was compared with a preprotocol cohort, which consisted of all children undergoing primary open CFR during the previous calendar year, 2012.
\end{abstract}

RESULTS There were 41 patients in the preprotocol and 39 in the postprotocol cohort. There was no statistical difference between the demographics of the 2 groups. When compared with the preprotocol cohort, intraoperative packed red blood cell transfusion volume decreased from $36.9 \pm 21.2 \mathrm{ml} / \mathrm{kg}$ to $19.2 \pm 10.9 \mathrm{ml} / \mathrm{kg} \mathrm{(} p=0.0001$ ), whereas fresh-frozen plasma transfusion decreased from $26.8 \pm 25.4 \mathrm{ml} / \mathrm{kg}$ to $1.5 \pm 5.7 \mathrm{ml} / \mathrm{kg}(\mathrm{p}<0.0001)$ following implementation of the protocol. Furthermore, estimated blood loss decreased from $64.2 \pm 32.4 \mathrm{ml} / \mathrm{kg}$ to $52.3 \pm 33.3 \mathrm{ml} / \mathrm{kg}(p=0.015)$. Use of fresh-frozen plasma in the postoperative period also decreased when compared with the period before implementation of the protocol. There was no significant difference in morbidity and mortality between the 2 groups.

CONCLUSIONS The results of this study suggested that using a multidisciplinary protocol consisting of transfusion algorithms and implementation of blood-sparing surgical techniques during major CFR in pediatric patients is associated with reduced intraoperative administration of blood product, without shifting the transfusion burden to the postoperative period.

http://thejns.org/doi/abs/10.3171/2015.3.PEDS14663

KEY WORDS craniosynostosis; thromboelastography; transfusion; blood-sparing surgical techniques; protocol; technique; fresh-frozen plasma

$\mathrm{B}$ LOOD transfusion is the most commonly performed medical procedure in health care in the US.,13,21 While the transfusion of blood products may be lifesaving for some patients, there is an abundance of compelling data implicating transfusions in increased morbidity and mortality in a variety of clinical settings. In critically ill children, blood transfusion is associated with increased mortality and prolonged ICU stay. ${ }^{11,25}$ Among pediatric patients undergoing open cardiac procedures, blood transfusion has been associated with increased risks of infection, renal failure, pulmonary complications, and mortality. ${ }^{34} \mathrm{In}$ adult patients, fresh-frozen plasma (FFP) has been associ-

ABBREVIATIONS ASA = American Society of Anesthesiologists; $C F R=$ craniofacial reconstruction surgery; EBL = estimated blood loss; FFP = fresh-frozen plasma; INR = international normalized ratio; $P C V=$ packed cell volume; $P R B C=$ packed red blood cells; $R O T E M=$ rotation thrombelastometry; TEG = thromboelastography. SUBMITTED December 29, 2014. ACCEPTED March 23, 2015.

INCLUDE WHEN CITING Published online July 31, 2015; DOI: 10.3171/2015.3.PEDS14663.

DISCLOSURE Dr. Austin is supported by NIH grant T32GM108554. 
ated with a higher risk of multiple organ failure and acute respiratory distress syndrome..$^{16,36}$ In addition to long-term sequelae, there are also immediate reactions to blood transfusion such as fluid overload, electrolyte disturbances, and allergic reactions. According to an analysis of Serious Hazards of Transfusion (SHOT) data, the incidence of adverse outcomes in children less than 18 years old is 18 in every 100,000 red cells transfused compared with 13 in every 100,000 in adults..$^{30}$

Craniofacial reconstruction surgery (CFR) is associated with significant blood loss and morbidity during the perioperative period. CFR is most often performed in patients with craniosynostosis, in which one or more skull sutures fuse early and cause stereotypical abnormal skull growth patterns. Depending on the involved suture(s), surgical intervention is performed to either reduce the risk of raised intracranial pressure later in life or to reduce the stigma of skull and secondary facial deformity. The majority of high-volume centers use a team approach in which both plastic surgeons with specialized training in craniofacial deformity and pediatric neurosurgeons are involved in the evaluation, intervention, and follow-up of these often complex cases. With the potential blood loss ranging from $20 \%$ to $500 \%$ of a patient's circulating blood volume, large-volume allogeneic blood transfusions are common during these procedures despite best surgical practice, which raises concerns regarding the aforementioned transfusion risks. ${ }^{38}$

At our institution, we noticed that blood transfusion volumes were high compared with other institutions. From a medical standpoint, we observed a need for an objective laboratory-guided protocol for transfusion management in CFR due to a high incidence of transfusion of blood products, based primarily on subjective coagulopathy. Because of a long turnaround time at our institution for international normalized ratio (INR) and partial thromboplastin time, we decided to devise and implement an algorithm using thromboelastography (TEG) to guide transfusion for FFP and conventional laboratory tests to guide transfusion of other blood products. From a surgical standpoint, blood-sparing surgical techniques during skin opening and craniotomy would be implemented to minimize blood loss intraoperatively. The purpose of this analysis was to determine whether a protocol consisting of blood-sparing surgical techniques and a transfusion algorithm would lead to decreased blood transfusion and estimated blood loss (EBL) for pediatric CFR patients. We also evaluated blood product administration postoperatively to analyze whether the transfusion burden was merely being transferred to this period.

\section{Methods}

\section{Protocol Implementation}

A proposed protocol for managing intraoperative blood product use and laboratory monitoring during CFR was developed by the perioperative team consisting of pediatric anesthesiologists, neurosurgeons, and a plastic surgeon (Fig. 1). This protocol was based largely on a review of current pediatric literature. ${ }^{19,26}$ When sound evidence was unavailable, local standard practices were used. The intra- operative CFR management protocol was implemented on January 1, 2013. Several weeks before implementation, the attending anesthesiologists and hands-on providers were debriefed to identify potential barriers to successful protocol implementation.

In general, for both cohorts, anesthesia was induced using nitrous oxide and sevoflurane, and large-bore intravenous access was obtained. An arterial line was placed for frequent blood sampling and direct blood pressure monitoring. An endotracheal tube was inserted for airway management, and crystalloid or 5\% albumin was used for fluid-deficit management and ongoing hourly fluid requirements. Aminocaproic acid was bolused at $100 \mathrm{mg} / \mathrm{kg}$ over 30 minutes, and an infusion of $33 \mathrm{mg} / \mathrm{kg} / \mathrm{hr}$ was continued after the bolus. Laboratory tests were performed before initiation of surgery, after bone osteotomies, if any provider suspected problems with coagulation, or at any time during the procedure when the team needed laboratory data. At the end of the procedure, the patient was extubated and brought to the postanesthesia care unit (PACU), where laboratory tests were performed. No patients received preoperative epogen or perioperative normovolemic hemodilution. Patients were then transported to the ICU where routine care was provided by the surgical and critical care teams. In the preprotocol cohort, anesthetic management was left to the discretion of the perioperative team, with no strict laboratory triggers for packed red blood cells (PRBC), FFP, platelets, or fibrinogen. Although there was no strict trigger for PRBC, many providers would transfuse to keep the packed cell volume $(\mathrm{PCV})>30$ and transfuse FFP when the INR was $>1.5$.

In the postprotocol cohort, the only difference in anesthetic management was the implementation of the transfusion algorithm (Fig. 1). Citrated TEG samples were hand delivered to our central laboratory, activated with kaolin, and the assay was performed using a Thrombelastograph analyzer (Haemonetics).

Standardized surgical technique in the postprotocol group included use of needle-tip monopolar electrocautery (Colorado needle, Stryker) for opening the skin and reflection of the skin flaps. Craniotomies were performed in the standard fashion with generous use of bone wax (Ethicon) and appropriate hemostatic agents including SURGICEL (Ethicon), GELFOAM (Pfizer), and SURGIFLO (Ethicon), where needed. Extra effort was made to reduce dural bleeding or overaggressive sagittal sinus manipulation.

The first 15 cases after guideline implementation were audited to ensure adherence to the transfusion algorithms. All of the surgical procedures were performed by a 2-person team consisting of 1 of 2 total neurosurgeons and 1 plastic surgeon using blood-sparing surgical techniques.

\section{Data Acquisition}

After approval by the Vanderbilt Institutional Review Board, we identified patients who underwent craniotomy for correction of craniosynostosis between January 1, 2012, and December 31, 2013, by querying our anesthetic records. Subjects were placed either in the preprotocol or postprotocol cohort based on date of surgery (before or after January 1, 2013). Demographics including age, sex, 


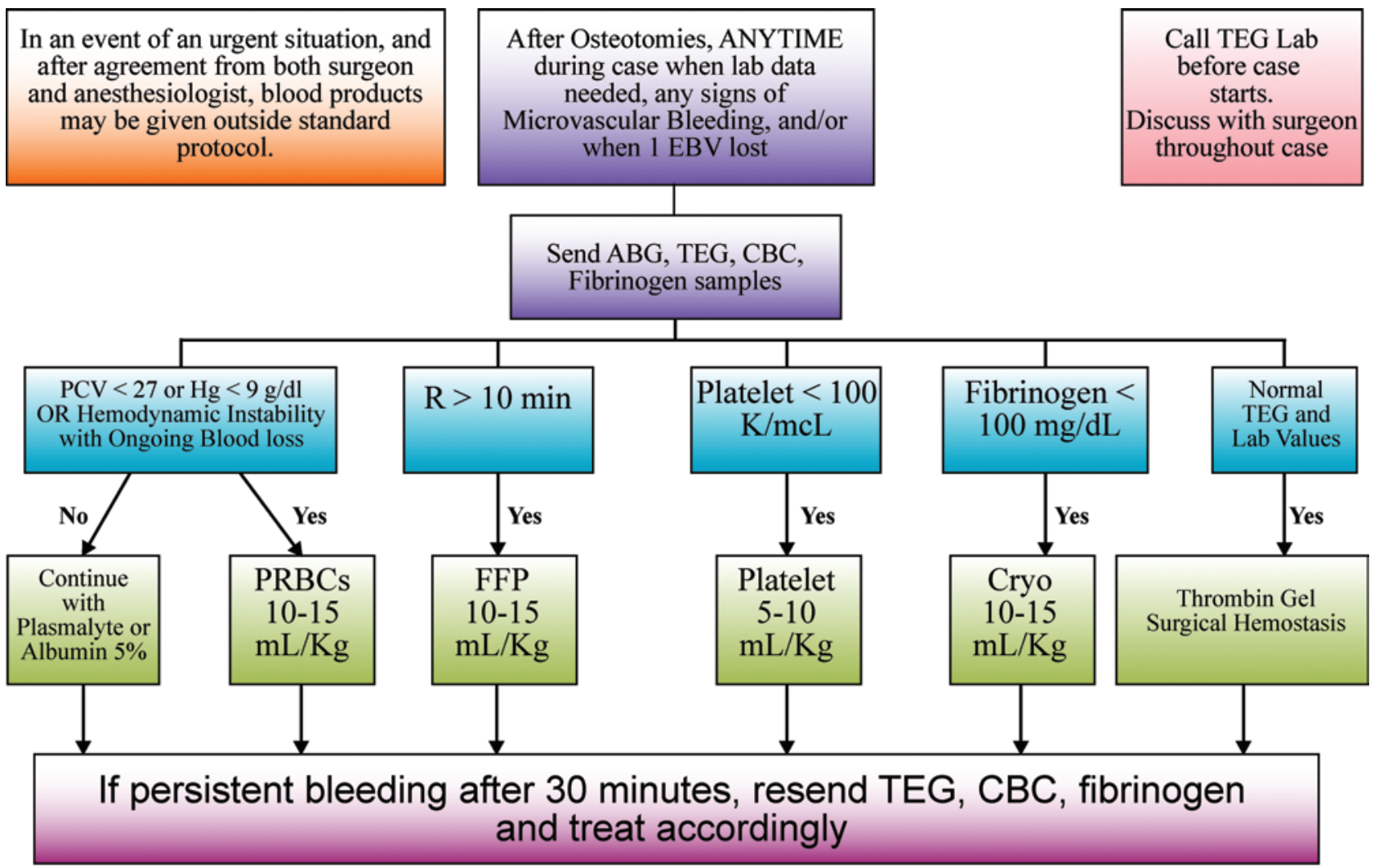

\section{Normal TEG and persistent bleeding $\rightarrow$ Stat Heme consult Treat accordingly}

FIG. 1. Transfusion algorithm. $A B G=$ arterial blood gas; $C B C=$ complete blood count; cryo = cryoprecipitate; $E B V=$ estimated blood volume; $\mathrm{Hg}=$ hemoglobin; $\mathrm{R}=$ reaction time. Figure is available in color online only.

weight, and American Society of Anesthesiologists (ASA) classification were obtained for each patient. The patients' medical histories and preoperative laboratory values were also obtained. Intraoperative variables regarding anesthetic regimen, surgical technique, and transfused blood products were recorded. Because only a few of the patients received 5\% albumin, this colloid amount was noted with crystalloid volume as total fluid volume. The EBL was calculated in a similar fashion to a previous study by Kearney et al. ${ }^{15}$ Postoperative data recorded included laboratory values, transfused blood products, ICU and hospital lengths of stay, and evidence of postoperative morbidity.

\section{Statistical Analysis}

All statistical analyses were performed using the $\mathrm{R}$ software package (version 2.15.1). Population characteristics were examined using the Student t-test with or without Welch's correction, Wilcoxon rank-sum test, Pearson's chi-square, or Fisher exact test, as appropriate for the distribution of the data. The Shapiro-Wilk test was used to determine normality of the sample sets. A p value $<0.05$ was considered statistically significant.

To further analyze the effect of the protocol, a multiple linear regression was then performed with total intraop- erative blood product administration (in milliliters per kilogram) as the response variable. Predictors included protocol, age, sex, craniosynostosis type, ASA classification score, preoperative INR, preoperative $\mathrm{PCV}$, preoperative platelet count, total crystalloid and colloid administered, lowest intraoperative temperature, and EBL. Multiple regression models were then created for each analysis, with the model that minimized the corrected Akaike information criterion selected as the best model. Residual normality was analyzed by assessing the linearity of quantilequantile plots and using the Shapiro-Wilk test, whereas heteroscedasticity was evaluated by producing scatterplots of residuals versus predicted values. Collinearity diagnostics were also performed through calculation of the variance inflation factor for the variables.

\section{Results}

During the year prior to implementation of the protocol (January 1, 2012, to December 31, 2012), 41 patients underwent primary open corrective craniotomy for craniosynostosis. In the year following implementation of the protocol (January 1, 2013, to December 31, 2013), 39 patients underwent primary open corrective craniotomy 
for craniosynostosis. All of these pre- and postprotocol patients were included in this analysis.

The demographic data for the pre- and postprotocol groups are displayed in Table 1. On univariate analysis, all demographic characteristics that were analyzed, including ASA physical status classification and synostosis types, were similar between the 2 populations. In addition to these characteristics, the preoperative laboratory values of the pre- and postprotocol cohorts were statistically comparable, as depicted in Table 2.

After implementation of the transfusion guidelines, intraoperative volume of transfusion of PRBC and FFP significantly decreased $(36.9 \mathrm{ml} / \mathrm{kg}$ vs $19.2 \mathrm{ml} / \mathrm{kg}$, p < $0.0001 ; 26.8 \mathrm{ml} / \mathrm{kg}$ vs $1.5 \mathrm{ml} / \mathrm{kg}, \mathrm{p}<0.0001$; respectively, Table 3). Furthermore, the incidence of FFP transfusion decreased significantly in the postprotocol group (35/41 preprotocol patients vs 3/39 postprotocol patients, p < 0.0001). As expected from the previous data, the total volume of blood product transfusion also significantly decreased after protocol implementation $(64.4 \mathrm{ml} / \mathrm{kg}$ vs 20.7 $\mathrm{ml} / \mathrm{kg}, \mathrm{p}<0.0001$ ). Total crystalloid and colloid administration increased in the postprotocol group $(37.5 \mathrm{ml} / \mathrm{kg}$ vs $61.0 \mathrm{ml} / \mathrm{kg}, \mathrm{p}<0.0001$, Table 4), whereas EBL decreased $(64.2 \mathrm{ml} / \mathrm{kg}$ vs $52.3 \mathrm{ml} / \mathrm{kg}, \mathrm{p}=0.015)$.

To account for possible confounding variables, a multiple linear regression was then performed with total blood products per kilogram as the response variable. This response variable was chosen due to residual normality and variance equality. The corrected Akaike information criterion-optimized model only included the protocol, age, ASA classification, synostosis type, and EBL as predictors (Table 5). After controlling for these potential confounders, the protocol was shown to decrease intraoperative blood product use by $31.6 \mathrm{ml} / \mathrm{kg}(95 \% \mathrm{CI}-41.5$ to -21.8 $\mathrm{ml} / \mathrm{kg}$ ) per patient. Thus, for an 8-kg patient, the protocol would decrease intraoperative transfusion by more than 1 unit of blood product on average.

\section{TABLE 1. Demographic data in 80 children who underwent CFR}

\begin{tabular}{cccc}
\hline \multicolumn{1}{c}{ Variable } & Preguidelines & Postguidelines & p Value \\
\hline No. of patients & 41 & 39 & \\
\hline Age $(\mathrm{mos})$ & $7.22 \pm 3.58$ & $7.67 \pm 6.28$ & 0.674 \\
\hline Weight $(\mathrm{kg})$ & $8.01 \pm 1.87$ & $8.22 \pm 2.17$ & 0.920 \\
\hline M/F $(\% \mathrm{M})$ & $28: 13(68.3 \%)$ & $31: 8(79.5 \%)$ & 0.314 \\
\hline ASA status & & & 0.519 \\
\hline 4 & $1(2.4 \%)$ & $0(0 \%)$ & \\
\hline 3 & $9(22.0 \%)$ & $6(15.4 \%)$ & \\
\hline 2 & $30(73.2 \%)$ & $30(76.9 \%)$ & \\
\hline 1 & $1(2.4 \%)$ & $3(7.7 \%)$ & \\
\hline Synostosis type & & & \\
\hline Metopic & $15(36.6 \%)$ & $15(38.5 \%)$ & \\
\hline Coronal & $3(7.3 \%)$ & $4(10.3 \%)$ & \\
\hline Sagittal & $18(43.9 \%)$ & $14(35.9 \%)$ & \\
\hline Lambdoidal & $2(4.9 \%)$ & $0(0 \%)$ & \\
\hline Multiple & $3(7.3 \%)$ & $6(15.4 \%)$ & \\
\hline
\end{tabular}

* Population statistics for nonproportional data expressed as mean \pm SD.
TABLE 2. Preoperative laboratory values in 80 children who underwent CFR*

\begin{tabular}{lccc}
\hline \multicolumn{1}{c}{ Value } & Preguidelines & Postguidelines & $p$ Value \\
\hline No. of patients & 41 & 39 & \\
\hline PCV & $34.7 \pm 3.4$ & $35.1 \pm 4.0$ & 0.340 \\
\hline INR & $1.00 \pm 0.07$ & $1.02 \pm 0.10$ & 0.544 \\
\hline Platelets $(1000 / \mu \mathrm{l})$ & $384 \pm 151$ & $432 \pm 130$ & 0.133 \\
\hline
\end{tabular}

* Population statistics for nonproportional data expressed as mean \pm SD.

Complete blood counts and INR were immediately analyzed on both cohorts upon arrival in the postanesthesia care unit. Despite variations in PRBC transfusion, PCV was similar in both groups (33.3 vs 32.0, $\mathrm{p}=0.340$, Table $6)$. INR was significantly increased in the postprotocol cohort (1.21 vs $1.29, \mathrm{p}=0.028)$, but there was not an increase in the frequency of critical INR values (defined as $\geq 1.5$ ) among the cohorts ( $4.9 \%$ vs $15.4 \%, p=0.150)$. Last, platelet counts were statistically higher in the postprotocol cohort $(187,000 / \mu l$ vs $284,000 / \mu l, p<0.0001)$.

To assess postoperative morbidity and outcome, various factors were analyzed in both cohorts. Although PRBC transfusion was similar between the 2 groups (26.7 $\mathrm{ml} / \mathrm{kg}$ vs $20.2 \mathrm{ml} / \mathrm{kg}, \mathrm{p}=0.962$, Table 7 ), there a significant decrease in FFP transfusion after protocol initiation (28.5 $\mathrm{ml} / \mathrm{kg}$ vs $0.8 \mathrm{ml} / \mathrm{kg}, \mathrm{p}<0.0001)$. Although the perioperative transfusion rates varied between the 2 cohorts, there

TABLE 3. Intraoperative transfusions in 80 children who underwent $\mathrm{CFR}^{*}$

\begin{tabular}{|c|c|c|c|}
\hline Transfused Products & Preguidelines & Postguidelines & $p$ Value \\
\hline No. of patients & 41 & 39 & \\
\hline PRBC (ml/kg) & $36.9 \pm 21.2$ & $19.2 \pm 10.9$ & $<0.0001$ \\
\hline $\begin{array}{l}\text { No. of patients with } \\
\text { transfusion of } \geq 1 \mathrm{U} \\
\text { PRBCs } \dagger\end{array}$ & $39(95.1 \%)$ & $34(87.2 \%)$ & 0.258 \\
\hline $\begin{array}{l}\text { No. of patients with } \\
\text { transfusion of }>1 \mathrm{U} \\
\text { PRBCs } \dagger\end{array}$ & $6(14.6 \%)$ & $0(0 \%)$ & 0.026 \\
\hline $\mathrm{FFP}(\mathrm{ml} / \mathrm{kg})$ & $26.8 \pm 25.4$ & $1.5 \pm 5.7$ & $<0.0001$ \\
\hline $\begin{array}{l}\text { No. of patients with } \\
\text { transfusion of } \geq 1 \mathrm{U} \\
\text { FFP† }\end{array}$ & $35(85.3 \%)$ & $3(7.7 \%)$ & $<0.0001$ \\
\hline $\begin{array}{l}\text { No. of patients with } \\
\text { transfusion of }>1 \mathrm{U} \\
\text { FFP† }\end{array}$ & $13(31.7 \%)$ & $0(0 \%)$ & $<0.0001$ \\
\hline Platelets (ml/kg) & $0.7 \pm 3.3$ & 0 & 0.165 \\
\hline $\begin{array}{l}\text { No. of patients with } \\
\text { transfusion of } \\
\text { platelets }\end{array}$ & $2(4.9 \%)$ & $0(0 \%)$ & 0.494 \\
\hline Total products $(\mathrm{ml} / \mathrm{kg})$ & $64.4 \pm 46.0$ & $20.7 \pm 14.2$ & $<0.0001$ \\
\hline
\end{tabular}

* Population statistics for nonproportional data expressed as mean \pm SD.

$\dagger$ All patients who received 1 or more units are included in the $\geq 1$ group. That is, if patients received 2 or more units, they are included in both the $>1$ and $\geq 1$ groups. If patients received only 1 unit, they are included only in the $\geq 1$ group. 
TABLE 4. Intraoperative variables in 80 children who underwent CFR*

\begin{tabular}{lccc}
\hline \multicolumn{1}{c}{ Variable } & Preguidelines & Postguidelines & $p$ Value \\
\hline No. of patients & 41 & 39 & \\
\hline Total crystalloid $(\mathrm{ml} / \mathrm{kg})$ & $37.5 \pm 21.3$ & $61.0 \pm 20.3$ & $<0.0001$ \\
\hline Urine $(\mathrm{ml} / \mathrm{kg})$ & $5.6 \pm 4.6$ & $6.7 \pm 7.7$ & 0.761 \\
\hline Low temp $\left({ }^{\circ} \mathrm{C}\right)$ & $36.1 \pm 0.4$ & $36.0 \pm 0.6$ & 0.354 \\
\hline $\mathrm{EBL}(\mathrm{ml} / \mathrm{kg})$ & $64.2 \pm 32.4$ & $52.3 \pm 33.3$ & 0.015 \\
\hline
\end{tabular}

* Population statistics for nonproportional data expressed as mean \pm SD.

were no statistically significant differences in drain output, ICU stay, and total hospital stay between the 2 populations.

To evaluate the overall impact of the protocol on transfusion during the hospital stay, total blood transfusion rates were compared between the 2 groups. Although there was a significant decrease in the intraoperative transfusion volume of PRBC given to these patients in the postprotocol group, all of these patients still required PRBC transfusion during the hospital stay (Table 8). On the other hand, the incidence of FFP transfusion was statistically significantly lower in the postprotocol group $(87.8 \%$ vs $10.3 \%$, $\mathrm{p}<0.0001)$. Finally, the mean discrete donor exposures decreased after protocol implementation (4.1 vs 1.4, p < 0.0001).

\section{Discussion}

In this retrospective study, the use of a protocol consisting of blood-sparing surgical techniques and a transfusion algorithm was associated with a decrease in total volume of transfusion of PRBC and FFP, without pushing the transfusion burden to the postoperative period.

Despite the decrease in total volume of blood transfusion, all patients required PRBC transfusion during the hospital stay. This may be due to high intraoperative blood loss and continued blood loss from drains postoperatively, resulting in large decreases in hematocrit. ${ }^{22}$ Furthermore, the number of patients exposed to multiple intraoperative units of FFP and PRBC was decreased in the postprotocol group. The total mean discrete donor exposure

TABLE 5. Multiple linear regression for intraoperative blood products*

\begin{tabular}{lccc}
\hline \multirow{2}{*}{ Characteristic } & \multicolumn{2}{c}{ Intraop Blood Products $(\mathrm{ml} / \mathrm{kg})$} & \\
\cline { 2 - 3 } & Estimate & $95 \% \mathrm{Cl}$ & p Value \\
\hline Protocol & -31.62 & -41.46 to -21.78 & $<0.0001$ \\
\hline Age (mos) & -0.68 & -1.61 to 0.26 & 0.1564 \\
\hline ASA classification & 12.71 & 6.33 to 19.09 & 0.0002 \\
\hline Synostosis type & -3.17 & -6.96 to 0.62 & 0.1003 \\
\hline EBL (ml/kg) & 2.13 & 1.72 to 2.54 & $<0.0001$ \\
\hline
\end{tabular}

* This ANCOVA model was generated using optimal selection based on the lowest corrected Akaike information criterion. Age and synostosis type were modeled as continuous variables and other characteristics were modeled as categorical variables. Adjusted $R^{2}$ for this model is 0.8492 .
TABLE 6. Immediate postoperative laboratory values in 80 children who underwent CFR*

\begin{tabular}{lccc}
\hline \multicolumn{1}{c}{ Value } & Preguidelines & Postguidelines & $p$ Value \\
\hline No. of patients & 41 & 39 & \\
\hline PCV & $33.3 \pm 6.3$ & $32.0 \pm 5.8$ & 0.340 \\
\hline INR & $1.21 \pm 0.14$ & $1.29 \pm 0.12$ & 0.028 \\
\hline $\begin{array}{l}\text { No. patients with INR } \\
\geq 1.5\end{array}$ & $2(4.9 \%)$ & $6(15.4 \%)$ & 0.150 \\
\hline $\begin{array}{l}\text { Platelets }(1000 / \mu l) \\
\text { * Population statistics for nonproportional data expressed as mean } \pm \text { SD. }\end{array}$
\end{tabular}

decreased to 1.4 units in the postprotocol cohort versus 4.1 units for the preprotocol cohort. Although our study was not powered to show a difference in mortality, decreasing the volume of blood transfusion and discrete donor exposures may have beneficial outcomes in patients, such as decreases in nosocomial infections, mechanical ventilation time, transfusion-related acute lung injury, viral infections, volume overload, electrolyte abnormalities, and mortality. ${ }^{17,18,20,37}$

Our protocol consisted of 4 main components used to reduce the perioperative transfusion rate: 1) the acceptance of lower hemoglobin levels; 2) standardization of transfusion triggers for platelets and fibrinogen using standard laboratory tests; 3) use of TEG to guide transfusion of FFP; and 4) use of blood-sparing surgical techniques. Lower hemoglobin level triggers have been demonstrated to be safe and to reduce transfusion in children undergoing CFR. ${ }^{31}$ Our algorithm produced results similar to those of other perioperative transfusion protocols based on lower transfusion criteria. Such protocols described in the adult literature have shown success in decreasing transfusions in their respective patient populations without increasing morbidity. ${ }^{2,29}$ Rouette et al. showed that postsurgical patients in the ICU who were restricted to

TABLE 7. Postoperative transfusion and length of ICU/hospital stay*

\begin{tabular}{lccc}
\hline \multicolumn{1}{c}{ Variable } & Preguidelines & Postguidelines & p Value \\
\hline No. of patients & 41 & 39 & \\
\hline PRBCs $(\mathrm{ml} / \mathrm{kg})$ & $26.7 \pm 40.4$ & $20.2 \pm 24.6$ & 0.962 \\
\hline $\begin{array}{l}\text { No. of patients with } \\
\text { transfusion of } \\
\text { PRBCs }\end{array}$ & $16(39.0 \%)$ & $17(43.6 \%)$ & 0.821 \\
\hline FFP (ml/kg) & $28.5 \pm 35.9$ & $0.8 \pm 4.9$ & $<0.0001$ \\
\hline $\begin{array}{l}\text { No. of patients with } \\
\text { transfusion of FFP }\end{array}$ & $23(56.1 \%)$ & $1(2.6 \%)$ & $<0.0001$ \\
\hline Total products (ml/kg) & $55.2 \pm 66.4$ & $21.0 \pm 24.4$ & 0.017 \\
\hline $\begin{array}{l}\text { Drain output (ml/first } \\
24 \text { hrs) }\end{array}$ & $137 \pm 83$ & $115 \pm 47$ & 0.573 \\
\hline $\begin{array}{l}\text { ICU stay (days) } \\
\text { Total hospital stay } \\
\text { (days) }\end{array}$ & $7.0 \pm 1.2$ & $4.1 \pm 1.1$ & 0.551 \\
\hline
\end{tabular}

* Population statistics for nonproportional data expressed as mean \pm SD. 
TABLE 8. Total transfusion throughout hospital stay*

\begin{tabular}{lccc}
\hline Transfusion Parameter & Preguidelines & Postguidelines & p Value \\
\hline No. of patients & 41 & 39 & \\
\hline $\begin{array}{l}\text { No. of patients with } \\
\text { transfusion of } \\
\text { PRBCs }\end{array}$ & $41(100 \%)$ & $39(100 \%)$ & 1.000 \\
\hline $\begin{array}{l}\text { No. of patients with } \\
\text { transfusion of FFP }\end{array}$ & $36(87.8 \%)$ & $4(10.3 \%)$ & $<0.0001$ \\
\hline $\begin{array}{l}\text { Mean discrete donor } \\
\text { exposures }\end{array}$ & $4.1 \pm 2.4$ & $1.4 \pm 0.5$ & $<0.0001$ \\
\hline
\end{tabular}

* Population statistics for nonproportional data expressed as mean \pm SD.

PRBC transfusion had no increase in morbidity or mortality, with shorter ICU length of stay compared with the liberal transfusion group. ${ }^{26}$ In pediatric patients undergoing cardiac surgery, conservative transfusion algorithms also reduced blood transfusion. ${ }^{19,39}$ Although there appears to be low use of intraoperative transfusion algorithms in CFR patients, recent publications have associated the use of protocols with decreased transfusion. ${ }^{6,32,35}$ Furthermore, experts in the field recommend transfusion protocols as a first-line approach to safely minimize transfusion in these patients. ${ }^{33}$ Surgical technique changes were not novel but only focused on reducing unnecessary blood loss during skin opening and craniotomy, similar to those used on all infants undergoing craniotomy or neurosurgical intervention at our institution since late 2012.

The incorporation of TEG into our transfusion algorithm was associated with a substantial decrease in FFP administration. The decrease in transfusion of FFP in our cohort is similar to that observed in reports of other TEGguided protocols. Shore-Lesserson et al. used a TEGguided transfusion algorithm in adult patients undergoing cardiac surgery and showed a decrease of FFP transfusion without an increase of chest tube drainage postoperatively. ${ }^{29}$ In a similar study in cardiac patients undergoing coronary artery bypass using a TEG-based transfusion algorithm, FFP and platelets were significantly decreased when compared with standard coagulation tests. ${ }^{2}$ Haas et al. recently associated a decrease in FFP administration in children undergoing CFR using rotation thrombelastometry (ROTEM) (Tem Systems), but had an increase in use of fibrinogen concentrates and factor XIII. ${ }^{12}$ It is not known if this finding can be correlated to TEG results because there is insufficient evidence that ROTEM data correlates directly with TEG data. ${ }^{23,27}$ In addition, there are variations in use of TEG versus ROTEM depending on the location of the institution. Many of the transfusion algorithms specify different hemostatic products, with TEG-based protocols recommending plasma, whereas ROTEM-based protocols recommend fibrinogen concentrate. ${ }^{4,28}$ The superiority of one test over the other is not known at this point.

Viscoelastic testing may offer a better view of coagulation by assessing the properties of whole blood. It is usually associated with faster result times and can be performed as a point-of-care test. ${ }^{8}$ A drawback to using TEG for guidance of the administration of FFP or other hemostatic factors is the availability of the equipment for testing. At our institution, there is only 1 TEG machine, which is located in a separate building from our hospital. To perform the test, a person has to hand-deliver the specimen to the laboratory, which can tie up limited human resources in a financially stressed environment. In addition, not all institutions have TEG equipment due to equipment and labor costs.

Apart from lower hemoglobin triggers and TEG use, several other techniques, such as autologous blood transfusions, preoperative erythropoietin, hemodilution, and blood salvage, have been used to reduce the intraoperative transfusion of allogeneic blood. ${ }^{7,14,31}$ More recent publications have cited antifibrinolytic use as a method of reducing PRBC transfusion. ${ }^{5,10}$ For example, aprotinin has been shown to decrease PRBC transfusion in children; unfortunately, aprotinin is not available for clinical use in the US. ${ }^{1}$ Of the available antifibrinolytic medications, tranexamic acid, either as a sole agent or combined with epoetin alfa, decreases PRBC transfusion and blood loss during the perioperative period for CFR without major complications. ${ }^{5,10}$ Although not as well studied, aminocaproic acid was associated with decreased transfusion volumes compared with patients not receiving it. ${ }^{24}$ At our institution, aminocaproic acid is on formulary, whereas tranexamic acid is not available.

\section{Limitations}

There are several limitations with this type of study. First, this analysis was performed as a retrospective study, which has inherent limitations. Although there was a decrease in blood product use after implementation of the protocol, this observed relationship may not have been causative; there could have been confounders that we were not able to appreciate. In addition, provider attitude may have changed due to the Hawthorne effect, leading to decreased transfusion. However, we believe that providers followed guidelines due to the $100 \%$ compliance to the protocol during initial auditing.

Regarding the postoperative care for these patients, transfusion triggers could have changed upon learning of protocol changes in the operating room during the study period, resulting in lower transfusion rates postoperatively. However, there were no changes in case volume or case complexity across the study interval. There was a change in neurosurgeon assigned to craniofacial cases and in ICU personnel focused on neurosurgical patients between study epochs, and this is a potential confounder. However, surgical technique clearly affects blood loss, and we thought this was overall highly contributory to the change seen between no-protocol and on-protocol. Although there was no impact noted over the current study interval, these data are currently being used to drive local postoperative protocol changes in an effort to reduce length of stay in the ICU and length of hospital stay overall. In addition, further study will focus on lowering transfusion triggers in the postoperative setting in an effort to further lower both ICU and hospital stay and exposure to blood products. We expect the data from this study to lead to a great deal of further local evolution of practice.

The transfusion triggers were based mostly on general pediatric literature because there is a paucity of data for 
children undergoing CFR. A recent publication by Goobie and Haas recommended very similar transfusion triggers for hemostatic products such as platelets and fibrinogen in North America. ${ }^{9}$ Some may argue that we should have used TEG parameters as triggers for fibrinogen and platelet administration and that the transfusion trigger for PRBC was too liberal. There were multiple reasons for not using the TEG results for fibrinogen and platelet administration. First, we did not want to implement too many changes at once, in order to get a higher rate of compliance. Thus, we planned to add more TEG parameters after the initial implementation of the new process. Second, the incidence of transfusion of platelets and cryoprecipitate has been historically low at our institution for these cases. With the low rate of transfusion of these products, we did not believe TEG would decrease administration of these hemostatic products. Despite the possible superiority of TEG to routine coagulation laboratory tests, the use of this modality to guide transfusion at many institutions appears to be minimal compared with the use of platelet count and fibrinogen. ${ }^{32}$ Regarding the liberal transfusion trigger for PRBC, we believed that a hemoglobin trigger of $9 \mathrm{~g} / \mathrm{dl}$ was appropriate in this type of surgery because these children have a small blood volume and the bleeding during this procedure can be rapid and may go undetected. We could have chosen a lower trigger such as $6-7 \mathrm{~g} / \mathrm{dl}$, but we believed that the risks outweighed the benefits. In addition, the incidence of transfusion of PRBC was very high in both groups and suggests that despite our changes in surgical and medical management, the transfusion of red blood cells is often required. Again, further study in this area is needed and is ongoing.

\section{Conclusions}

The implementation of a protocol consisting of bloodsparing surgical techniques and a transfusion algorithm was associated with a clinically significant decrease in the intraoperative administration of the total volume of blood products and EBL in children undergoing CFR, without pushing the transfusion burden to the postoperative period. Postoperative drain output and complications were similar between the 2 groups. These results suggest that blood-sparing surgical techniques and transfusion algorithms may decrease transfusion compared with routine management, without an observable decrement in patient outcome. Further studies are needed to delineate specific relationships between transfusion, length of ICU/hospital stay, outcomes, and hospital cost.

\section{Acknowledgments}

We wish to acknowledge Elizabeth Beazley, RN, and Brian Donahue, MD, Associate Professor of Anesthesiology; both at Vanderbilt University.

\section{References}

1. Ahmed Z, Stricker L, Rozzelle A, Zestos M: Aprotinin and transfusion requirements in pediatric craniofacial surgery. Paediatr Anaesth 24:141-145, 2014

2. Ak K, Isbir CS, Tetik S, Atalan N, Tekeli A, Aljodi M, et al: Thromboelastography-based transfusion algorithm reduces blood product use after elective CABG: a prospective randomized study. J Card Surg 24:404-410, 2009

3. Arulselvi S, Rangarajan K, Sunita S, Misra MC: Blood transfusion practices at a level one trauma centre: a one-year retrospective review. Singapore Med J 51:736-740, 2010

4. Coakley M, Reddy K, Mackie I, Mallett S: Transfusion triggers in orthotopic liver transplantation: a comparison of the thromboelastometry analyzer, the thromboelastogram, and conventional coagulation tests. J Cardiothorac Vasc Anesth 20:548-553, 2006

5. Dadure C, Sauter M, Bringuier S, Bigorre M, Raux O, Rochette A, et al: Intraoperative tranexamic acid reduces blood transfusion in children undergoing craniosynostosis surgery: a randomized double-blind study. Anesthesiology 114:856861, 2011

6. Duncan C, Richardson D, May P, Thiruchelvam J, Shong DC, Potter F, et al: Reducing blood loss in synostosis surgery: the Liverpool experience. J Craniofac Surg 19:1424-1430, 2008

7. Fearon JA: Reducing allogenic blood transfusions during pediatric cranial vault surgical procedures: a prospective analysis of blood recycling. Plast Reconstr Surg 113:1126-1130, 2004

8. Ganter MT, Hofer CK: Coagulation monitoring: current techniques and clinical use of viscoelastic point-of-care coagulation devices. Anesth Analg 106:1366-1375, 2008

9. Goobie SM, Haas T: Bleeding management for pediatric craniotomies and craniofacial surgery. Paediatr Anaesth 24:678-689, 2014

10. Goobie SM, Meier PM, Pereira LM, McGowan FX, Prescilla RP, Scharp LA, et al: Efficacy of tranexamic acid in pediatric craniosynostosis surgery: a double-blind, placebo-controlled trial. Anesthesiology 114:862-871, 2011

11. Guzzetta NA: Benefits and risks of red blood cell transfusion in pediatric patients undergoing cardiac surgery. Paediatr Anaesth 21:504-511, 2011

12. Haas T, Goobie S, Spielmann N, Weiss M, Schmugge M: Improvements in patient blood management for pediatric craniosynostosis surgery using a ROTEM ${ }^{\circledR}$-assisted strategyfeasibility and costs. Paediatr Anaesth 24:774-780, 2014

13. Haspel RL, Uhl L: How do I audit hospital blood product utilization? Transfusion 52:227-230, 2012

14. Helfaer MA, Carson BS, James CS, Gates J, Della-Lana D, Vander Kolk C: Increased hematocrit and decreased transfusion requirements in children given erythropoietin before undergoing craniofacial surgery. J Neurosurg 88:704-708, 1998

15. Kearney RA, Rosales JK, Howes WJ: Craniosynostosis: an assessment of blood loss and transfusion practices. Can J Anaesth 36:473-477, 1989

16. Khan H, Belsher J, Yilmaz M, Afessa B, Winters JL, Moore $\mathrm{SB}$, et al: Fresh-frozen plasma and platelet transfusions are associated with development of acute lung injury in critically ill medical patients. Chest 131:1308-1314, 2007

17. Kipps AK, Wypij D, Thiagarajan RR, Bacha EA, Newburger JW: Blood transfusion is associated with prolonged duration of mechanical ventilation in infants undergoing reparative cardiac surgery. Pediatr Crit Care Med 12:52-56, 2011

18. Kneyber MC, Hersi MI, Twisk JW, Markhorst DG, Plötz FB: Red blood cell transfusion in critically ill children is independently associated with increased mortality. Intensive Care Med 33:1414-1422, 2007

19. Lacroix J, Hébert PC, Hutchison JS, Hume HA, Tucci M, Ducruet T, et al: Transfusion strategies for patients in pediatric intensive care units. N Engl J Med 356:1609-1619, 2007

20. Lavoie J: Blood transfusion risks and alternative strategies in pediatric patients. Paediatr Anaesth 21:14-24, 2011

21. Murphy MF, Stanworth SJ, Yazer M: Transfusion practice and safety: current status and possibilities for improvement. Vox Sang 100:46-59, 2011

22. Nguyen TT, Lam HV, Phillips M, Edwards C, Austin TM: 
Intraoperative optimization to decrease postoperative PRBC transfusion in children undergoing craniofacial reconstruction. Paediatr Anaesth 25:294-300, 2015

23. Nielsen VG: A comparison of the Thrombelastograph and the ROTEM. Blood Coagul Fibrinolysis 18:247-252, 2007

24. Oppenheimer AJ, Ranganathan K, Levi B, Strahle JM, Kapurch J, Muraszko KM, et al: Minimizing transfusions in primary cranial vault remodeling: the role of aminocaproic acid. J Craniofac Surg 25:82-86, 2014

25. Redlin M, Kukucka M, Boettcher W, Schoenfeld H, Huebler M, Kuppe H, et al: Blood transfusion determines postoperative morbidity in pediatric cardiac surgery applying a comprehensive blood-sparing approach. J Thorac Cardiovasc Surg 146:537-542, 2013

26. Rouette J, Trottier H, Ducruet T, Beaunoyer M, Lacroix J, Tucci M: Red blood cell transfusion threshold in postsurgical pediatric intensive care patients: a randomized clinical trial Ann Surg 251:421-427, 2010

27. Sankarankutty A, Nascimento B, Teodoro da Luz L, Rizoli $\mathrm{S}$ : TEG ${ }^{\circledR}$ and ROTEM ${ }^{\circledR}$ in trauma: similar test but different results? World J Emerg Surg 7 (Suppl 1):S3, 2012

28. Schöchl H, Nienaber U, Hofer G, Voelckel W, Jambor C, Scharbert G, et al: Goal-directed coagulation management of major trauma patients using thromboelastometry (ROTEM)guided administration of fibrinogen concentrate and prothrombin complex concentrate. Crit Care 14:R55, 2010

29. Shore-Lesserson L, Manspeizer HE, DePerio M, Francis S, Vela-Cantos F, Ergin MA: Thromboelastography-guided transfusion algorithm reduces transfusions in complex cardiac surgery. Anesth Analg 88:312-319, 1999

30. Stainsby D, Jones H, Wells AW, Gibson B, Cohen H: Adverse outcomes of blood transfusion in children: analysis of UK reports to the serious hazards of transfusion scheme 19962005. Br J Haematol 141:73-79, 2008

31. Steinbok P, Heran N, Hicdonmez T, Cochrane DD, Price A: Minimizing blood transfusions in the surgical correction of coronal and metopic craniosynostosis. Childs Nerv Syst 20:445-452, 2004

32. Stricker PA, Cladis FP, Fiadjoe JE, McCloskey JJ, Maxwell LG: Perioperative management of children undergoing craniofacial reconstruction surgery: a practice survey. Paediatr Anaesth 21:1026-1035, 2011

33. Stricker PA, Fiadjoe JE: Anesthesia for craniofacial surgery in infancy. Anesthesiol Clin 32:215-235, 2014

34. Székely A, Cserép Z, Sápi E, Breuer T, Nagy CA, Vargha P, et al: Risks and predictors of blood transfusion in pediatric patients undergoing open heart operations. Ann Thorac Surg 87:187-197, 2009

35. Vega RA, Lyon C, Kierce JF, Tye GW, Ritter AM, Rhodes JL: Minimizing transfusion requirements for children undergoing craniosynostosis repair: the CHoR protocol. J Neurosurg Pediatr 14:190-195, 2014

36. Watson GA, Sperry JL, Rosengart MR, Minei JP, Harbrecht BG, Moore EE, et al: Fresh frozen plasma is independently associated with a higher risk of multiple organ failure and acute respiratory distress syndrome. J Trauma 67:221-230, 2009

37. White M, Barron J, Gornbein J, Lin JA: Are red blood cell transfusions associated with nosocomial infections in pediatric intensive care units? Pediatr Crit Care Med 11:464468, 2010

38. White N, Marcus R, Dover S, Solanki G, Nishikawa H, Millar C, et al: Predictors of blood loss in fronto-orbital advancement and remodeling. J Craniofac Surg 20:378-381, 2009

39. Whitney G, Daves S, Hughes A, Watkins S, Woods M, Kreger $\mathrm{M}$, et al: Implementation of a transfusion algorithm to reduce blood product utilization in pediatric cardiac surgery. Paediatr Anaesth 23:639-646, 2013

\section{Author Contributions}

Conception and design: Nguyen, Hill, Austin, Whitney, Lam. Acquisition of data: Nguyen, Hill, Austin, Lam. Analysis and interpretation of data: all authors. Drafting the article: all authors. Critically revising the article: all authors. Reviewed submitted version of manuscript: all authors. Approved the final version of the manuscript on behalf of all authors: Nguyen. Statistical analysis: Nguyen, Austin.

\section{Supplemental Information}

\section{Previous Presentation}

Portions of this work were presented in abstract form on May 18, 2014, at the International Anesthesia Research Society Annual Meeting, held in Montreal, Quebec, Canada.

\section{Correspondence}

Thanh T. Nguyen, Department of Anesthesiology, Vanderbilt University, 2200 Children's Way, Ste. 3116, Nashville, TN 37232. email: ttnguyen16@gmail.com. 